\title{
Splenic Hydatid Cyst: A Case Report
}

S. Tadsaoui*, A. Chehboun, B. Boutakioute, M. Ouali Idrissi, N. Cherif Idrissi El Ganouni

Radiology Department, Arrazi Hospital, Mohammed VI university hospital, Marrakech, Morocco

DOI: $10.36347 /$ simcr.2020.v08i12.017

| Received: 21.10.2020 | Accepted: 05.11.2020 | Published: 30.12.2020

*Corresponding author: Samira Tadsaoui

Abstract

Hydatidosis is an antropozoonosis caused by the larval form of the cestode of the genus echinococcus granulosus. Despite the endemic state of the disease in some countries of the Mediterranean basin, splenic hydatidosis is rare. It comes in 3rd position after the liver and the lung localization. The treatment is mainly surgical. We report the case of a 21-year-old patient living in a rural area around Marrakech, with no particular medical history, who presented with pain in the left hypochondrium that had developed for seven months revealing a splenic hydatid cyst on ultrasound with positive hydatid serology. The abdominal CT scan showed a hydatid splenic cyst with a membrane detachment occupying almost the entire splenic parenchyma. The patient underwent a resection of the protruding dome, the evolution of which was simple.

Keywords: Hydatid cyst, Spleen, Resection of the protruding dome.

Copyright $\odot 2020$ The Author(s): This is an open-access article distributed under the terms of the Creative Commons Attribution 4.0 International License (CC BY-NC 4.0) which permits unrestricted use, distribution, and reproduction in any medium for non-commercial use provided the original author and source are credited.

\section{INTRODUCTION}

Hydatidosis is an endemic anthropozoonosis in countries around the Mediterranean and in Latin America. Its preferentially develops in liver and lungs. Splenic localization is rare $(0.9$ to $8.2 \%)$ [2-4.The clinical symptoms are nonspecific and late, ultrasound is often sufficient to make the diagnosis and the treatment is mainly surgical.

\section{Case Report}

A 21-year-old woman, with no particular medical or surgical history, living in a rural region around Marrakech, presented with pain in the left hypochondrium that has been evolving for seven months, in a context of apyrexia without neither anorexia nor weight loss.

Clinical examination revealed tenderness of the hypochondrium and left flank with splenomegaly. On blood tests: white blood cells at 5760/mm3; hemoglobin at $13 \mathrm{~g} / \mathrm{dl}$, with a positive hydatidosis serology at 10240 .

Abdominal ultrasound showed an enlarged spleen measuring $13.5 \mathrm{~cm}$ on long axis, seat of a cystic lesion, measuring 10x9 cm, rounded in shape,well limited, thin-walled, with finely echogenic content, and individualization of some detached membranes, nonvascularized on doppler color (figure 1).
The CT scan revealed splenomegaly with a roughly rounded cyst lesion, hypodense, site of membranes (Figure 2). The patient underwent resection of the protruding dome. Medical antiparasitic treatment with Albendazole was prescribed after surgery. The outcome has been favorable.

\section{DISCUSSION}

Hydatidosis is a helminthiasis caused by the development in humans of the larval form of echinococcus granulosus. The definitive host is most often the dog [1]. The intermediate host, contaminated by the digestive tract, is most often sheep and accidentally humans [1]. The embryo then crosses the intestinal wall, reaches the liver (1st filter), through the portal vein to locate there or to reach the lungs (2nd filter) via the vena cava, then any other organ via systemic circulation. Hydatid cyst is therefore most often localized in the liver and then in the lungs [1]. The splenic localization comes in $3 \mathrm{rd}$ position. Other ways of splenic involvement have been suggested: involvement by contiguity (gastric or colonic transparietal) the lymphatic tract and the retrograde portosplenic venous route [4].

In 20 to $62.5 \%$ of cases, splenic hydatid cyst is associated with other hydatid localizations, in particular hepatic or peritoneal [4]. The development of splenic hydatid cyst is pauci symptomatic and slow with a clinical latency phase of 2 to 20 years. The most 
common reasons for consultation are pain followed by the finding of a mass in the left hypochondrium (or splenomegaly) and the incidental finding [2, 3]. Abscedation, fissuring with anaphylaxis, and rupture in the pleura, stomach, colon, or skin are the complications that can indicate the disease.

Abdominal ultrasound, CT and MRI are the most useful diagnostic options showing cystic calcifications, vesicles or intracystic septa [6]. They are associated with positive hydatid serology for a better diagnostic certainty. These examinations also allow the diagnosis of asymptomatic and polyvisceral forms [2].

Ultrasound staging of hydatic liver cyst is based on Gharbi's classification [5]. Abdominal and thoracic X-rays can objectify calcification or a mass of liquid tone that projects into the lung or splenic area.

The splenic hydatid cyst should be treated surgically, due to the high risk of rupture. The most commonly used procedure in adults is standard splenectomy, but the surgical technique should be chosen according to the size of the cyst and its location [7]. Prevention relies on public health education, veterinarian control veterinarian of slaughter of stray dogs with the census and deworming of domestic dogs.

\section{CONCLUSION}

The hydatid cyst must be evoked in the presence of any cystic lesion in endemic countries, but also in developed countries due to the migratory flow of populations. Splenic localization is rare. It can be suspected on a range of epidemiological, biological and ultrasound arguments. The treatment is surgical. The best treatment remains preventive through health education of the rural population.

\section{Conflicts of interest}

The authors declare no conflict of interest.

\section{Contributions from authors}

All authors have read and approved the final version of the manuscript.

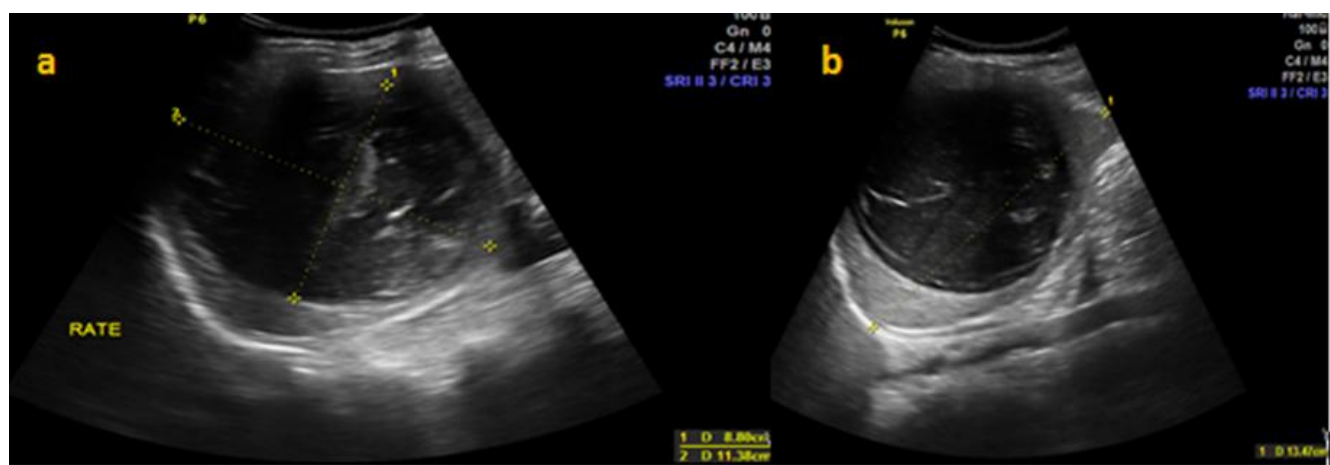

Fig-1: abdominal ultrasound: splenomegaly (a) site of a cystic lesion, with finely echogenic content, with individualization of a few detached septas with no vascularisation on doppler color (b), evoking a splenic hydatid cyst II of the GHARBI classification

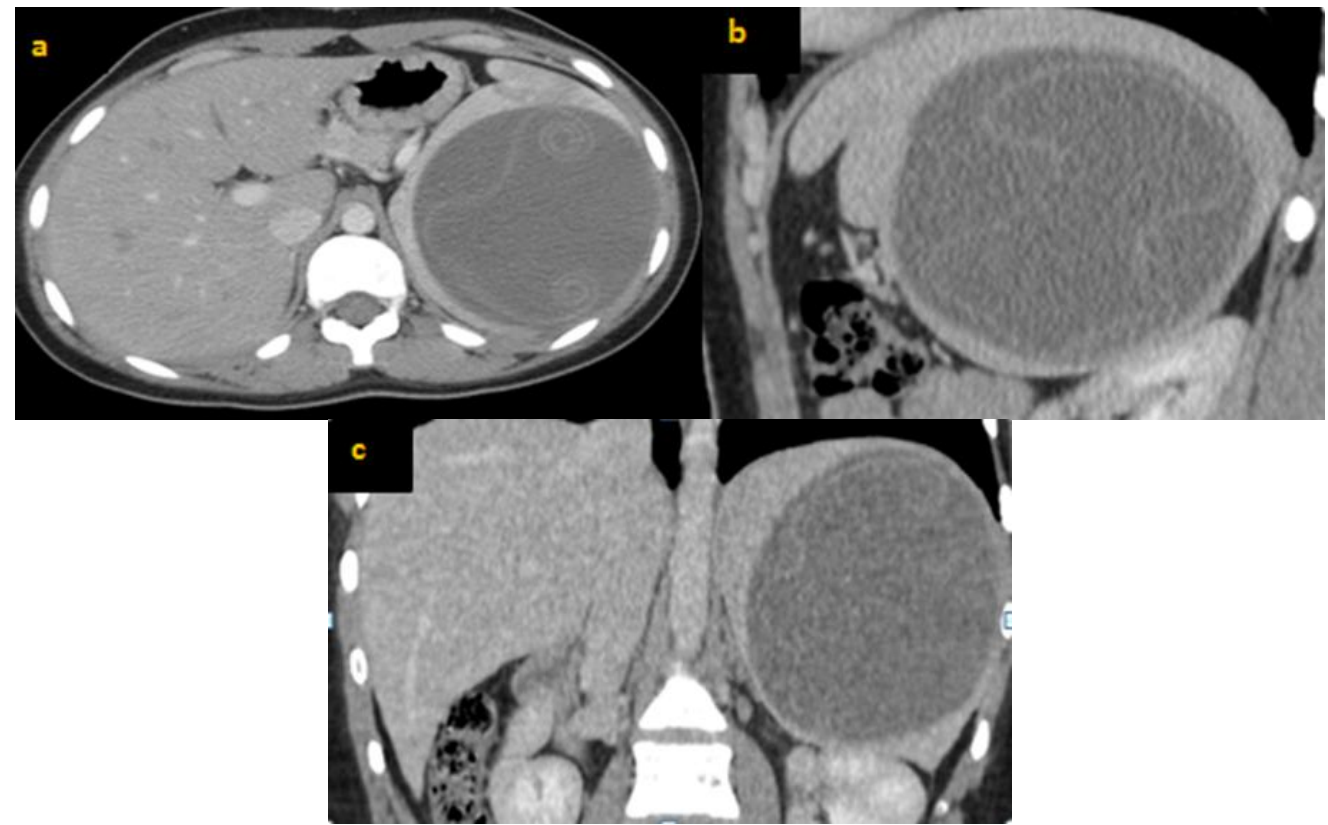

Fig-2: abdominal CT in portal phase, axial slices (a), sagittal (b) and coronal (c) reconstruction: splenomegaly site of a coarsely rounded cystic formation, hypodense, site of septa detachment 


\section{REFERENCES}

1. Abi F, El Fares F, Khaiz D, Bouzidi A. Les localisations inhabituelles du kyste hydatique: a propos de 40 cas. J Chir. 1989;126:307-12.

2. Moumen M, El Alaoui M, Mokhtari M, El Fares F. Pour un traitement conservateur du kyste hydatique de la rate. J Chir. 1991;128:260-2.

3. Berrada S, Ridai M, Mokhtari M. Kystes hydatiques de la rate: splénectomies ou chirurgie conservatrice?. Ann Chir. 1991;45:434-6.

4. Bourgeon R, Catalano H, Pantin JP. L'échinococcose splénique. J Chir. 1960;80:60832.
5. Gharbi HA, Hanine W, Brauner MW, Dupuch K. Ultrasound examination of the hydatic liver. Radiology. 1981; 139:459-63.

6. Touré Alpha Oumar, Kâ Ibrahima, Sarr Ibrahima Sitor, Cissé Mamadou, Konaté Ibrahima, Kâ Ousmane, Dieng Madieng, Dia Abdarahmane, Touré Cheikh Tidiane .Kyste hydatique de la rate : à propos d'un cas, Pan African Medical Journal. 2013; 14: 92.

7. Bounaim A, Zentar A, Ali AA, El Kaoui H, Sair K. Kyste hydatique primitif de la rate: deux cas. Peuton être conservateurs?. Journal africain d'hépatogastroentérologie. 2009 Mar 1;3(1):46-8. 